\section{THE TUMOR MICROBIOME CORRELATES WITH RESPONSE TO IMMUNE CHECKPOINT INHIBITORS IN RENAL CELL CARCINOMA}

Caroline Wheeler*, Yuanquan Yang, Daniel Spakowicz, Rebecca Hoyd, Mingjia Li. The Ohio State University Comprehensive Cancer Center, Columbus, OH, USA

Background Immune checkpoint inhibitor therapy, or ICI, is currently the most successful treatment option for patients with renal cell carcinoma (RCC). However, only $20 \%$ of patients have a durable response, ${ }^{1}$ driving a significant need to improve treatment outcomes. The tumor microbiome has recently been shown to play a role in chemotherapy-based treatment outcomes, but, to our knowledge, no study has explored its role in response to ICIs. ${ }^{2-4}$

Methods Tumor samples were collected from 22 patients with RCC as a part of the Total Cancer Care program at The Ohio State University Comprehensive Cancer Center. Raw RNA-seq reads from these biopsies, as well as data on the responses to ICI therapy were collected. Response evaluation was based on RECIST v1.1 criteria with complete or partial response, or stable disease classified as "Responders,", and progressive disease classified as "Non-responsders". The RNAseq reads were processed through a pipeline developed by the Spakowicz lab, known as ExoTIC (Exogenous sequences in Tumor and Immune Cells), to carefully identify exogenous sequences. ${ }^{5}{ }^{6}$ Reads that don't align to the human reference genome are meticulously filtered of (1) common laboratory contaminants, (2) taxa that inversely correlate with input RNA quantity, and (3) taxa commonly found in the negative controls of microbiome experiments. DESeq2 was used to perform a differential abundance analysis on the comparison groups at every taxonomic level.

Results The 22 patients with RCC range from 22 to 74 years of age at diagnosis, are $72.7 \%$ male, and $54.5 \%$ responded to ICIs. Exogenous taxa are identified in the tumor RNAseq, including bacteria, fungi, and viruses (figure 1). Within the tumors responsive to immunotherapy, there was found to be a significant enrichment of certain microbial species, including Bacillus thuringiensis, Comamonas testosteroni, Colletotrichum higginsianum, and Elaeis guineesis. Comparatively, the cohort of non-responsive tumors was found to have a significant enrichment of Candidatus Promineofilum breve, Clostridioides difficile, Nocardia cyriacigeorgica, Streptomyces sp. CdTB01, and Streptomyces venezuelae (figure 2).

Conclusions We found that prior to ICI treatment the tumor microbiome of patients with RCC whose tumors responded to immunotherapy vary from those that did not respond to treatment. This implies that a therapeutic target to modify the tumor microbiome to improve treatment outcomes. Future research will evaluate whether these correlations are causally associated with outcomes and will evaluate their effect on the tumor microenvironment including immune cell infiltration.

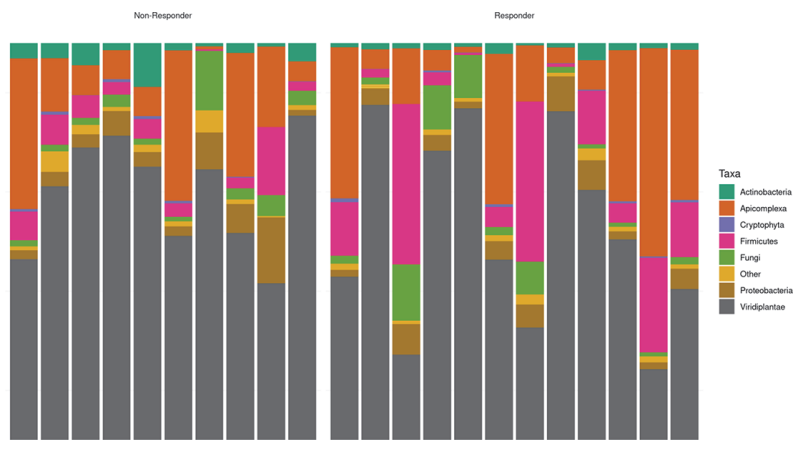

Abstact 942 Figure 1 Relative abundances of exogenous taxa found in tumor RNAseq are shown in a stacked bar plot

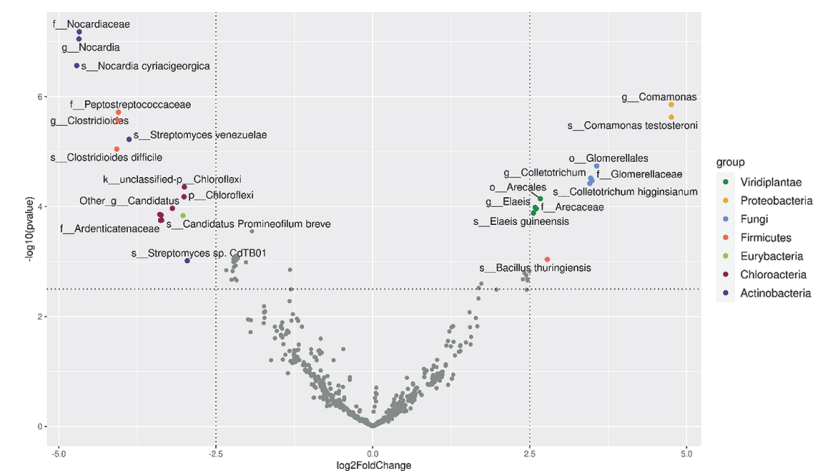

Abstact 942 Figure 2 Differential abundance analysis of taxa found within tumor RNAseq data by the exotic pipeline. Colored points represent significantly (pvalue $<0.05$ ) enriched taxa with a high $(>2.5)$ fold-difference in abundance between the groups

Acknowledgements The authors acknowledge the support and resources of the Ohio Supercomputing Center (PAS1695).

\section{REFERENCES}

1. Ciccarese C, Di Nunno V, lacovelli R, Massari F. Future perspectives for personalized immunotherapy in renal cell carcinoma. Expert opinion on biological therapy. Taylor \& Francis. 2017;17(9):1049-1052.

2. Geller LT, Barzily-Rokni M, Danino T, Jonas OH, Shental N, Nejman D, Gavert N, Zwang Y, Cooper ZA, Shee K, Thaiss CA, Reuben A, Livny J, Avraham R, Frederick DT, Ligorio M, Chatman K, Johnston SE, Mosher CM, Brandis A, Fuks G, Gurbatri C, Gopalakrishnan V, Kim M, Hurd MW, Katz M, Fleming J, Maitra A, Smith DA, Skalak M, Bu J, Michaud M, Trauger SA, Barshack I, Golan T, Sandbank J, Flaherty KT, Mandinova A, Garrett WS, Thayer SP, Ferrone CR, Huttenhower C, Bhatia SN, Gevers D, Wargo JA, Golub TR, Straussman R. Potential role of intratumor bacteria in mediating tumor resistance to the chemotherapeutic drug gemcitabine. Science 2017 September 15;357(6356):1156-1160. PMID: 28912244.

3. Nejman D, Livyatan I, Fuks G, Gavert N, Zwang Y, Geller LT, Rotter-Maskowitz A, Weiser R, Mallel G, Gigi E, Meltser A, Douglas GM, Kamer I, Gopalakrishnan V, Dadosh T, Levin-Zaidman S, Avnet S, Atlan T, Cooper ZA, Arora R, Cogdill AP, Khan MAW, Ologun G, Bussi Y, Weinberger A, Lotan-Pompan M, Golani O, Perry 
G, Rokah M, Bahar-Shany K, Rozeman EA, Blank CU, Ronai A, Shaoul R, Amit A, Dorf-man T, Kremer R, Cohen ZR, Harnof S, Siegal T, Yehuda-Shnaidman E, Gal-Yam EN, Shapira H, Baldini N, Langille MGl, Ben-Nun A, Kaufman B, Nissan A, Golan T, Dadiani M, Levanon K, Bar J, Yust-Katz S, Barshack I, Peeper DS, Raz DJ, Segal E, Wargo JA, Sandbank J, Shental N, Straussman R. The human tumor microbiome is composed of tumor type-specific intracellular bacteria. Science 2020 May 29:368(6494):973-980.

4. Poore GD, Kopylova E, Zhu Q, Carpenter C, Fraraccio S, Wandro S, Kosciolek T, Janssen S, Metcalf J, Song SJ, Kanbar J, Miller-Montgomery S, Heaton R, Mckay $R$, Patel $S P$, Swafford $A D$, Knight R. Microbi-ome analyses of blood and tissues suggest cancer diagnostic approach. Nature 2020;579(7800):567-574. PMID: 32214244.

5. Malalur, Pannaga, Mo, Xiaokui, Hoyd, Rebecca, Hays, John, Carbone, David, Spakowicz, Daniel. Investigating intra-tumor microbes, blood microbes, and CEA for development of non-invasive biomarkers in colorectal cancer. Journal of Clinical Oncology 2021:39(15 suppl): 3551-3551.

6. Malalur PG, Mo X, Hoyd R, Carbone DP, Spakowicz D. Intra-tumoral microbes and overall survival in colorectal cancer patients. Journal of Clinical Oncology 2020;38(15_suppl):4083-4083.

Ethics Approval Data were obtained through an IRB-approved Honest Broker protocol (2015H0185) supporting the Total Cancer Care protocol $2013 \mathrm{H} 0199$.

http://dx.doi.org/10.1136/jitc-2021-SITC2021.942 